\title{
Linguistic Problems in Light of General Semiotics
}

\author{
Solomonick Abraham \\ Retired from the Ministry of Education, Jerusalem, Israel
}

\section{Email address:}

semiosol@netvision.net.il

\section{To cite this article:}

Solomonick Abraham. Linguistic Problems in Light of General Semiotics. International Journal of Language and Linguistics. Vol. 9, No. 4, 2021, pp. 206-214. doi: 10.11648/j.ijl1.20210904.20

Received: June 22, 2021; Accepted: July 14, 2021; Published: July 22, 2021

\begin{abstract}
This article is based on several primary postulates. Here is the leading one: A science, called semiotics, which is rapidly developing before our eyes, has not yet developed a standard and acceptable scientific paradigm for most of its followers. It is interpreted in various ways by schools that have arisen in different countries, relying on completely different positions. The school from the Estonian city of Tartu, for example, is guided by the fact that all signs arose in inanimate nature and continued in the life of plants and all living beings, including humans. Thus, any cause leading to the same effect is a sign for this effect. The semiotic school in Gothenburg (Sweden) defends the thesis that images are the basis of all other sign formations. Many semioticians, following de Saussure, are convinced that linguistic signs are the leading and initial ones, and all other sign constructs follow them. The author of this work proceeds from the assumption that the symbolic storehouse contains signs for very different content and of very different origins. From natural signs that came to us from nature (we see smoke, it means something is burning; we hear thunder, it means that it is raining somewhere), to signs in mathematics, which all came from the human mind. Language constructions are included in this system along with signs of other types. None of these types is the leading and decisive one; all of them were born in the course of the development of human civilization, as the human spirit strengthened and developed. And each of them performs its own function - for example, images underlie all arts, and languages are called upon to explain everything and everyone. Therefore, each type of sign is specific, and all together they make up a complete set of tools with which we can understand the events taking place around us and influence them. A complete and deep explanation of the entire sphere of signs and sign systems is available only to general semiotics - it determines the place of each specific sign topic. This article is devoted to the definition of the possibilities of linguistic signs it seems to be objective enough and it presents linguistic manifestations familiar to us in a new way. What is a word? What is grammar? What is lexicography? etc. But it presents them from a different point of view, from the point of view of semiotics.
\end{abstract}

Keywords: Language Sign Systems, The Word as the Basic Language-system Sign,

Grammars and Dictionaries as Metalanguage, Linguistic Sign System Logic

\section{Introduction}

The first person to call the words of a language "signs" was John Locke (1632 - 1704), but he did not expand on the nature of signs and the science that could study them.

"Locke would use the term sem(e)iotike in 'An Essay Concerning Human Understanding' (book IV, chap. 21), in which he explains how science may be divided into three parts: "All that can fall within the compass of human understanding, being either, first, the nature of things, as they are in themselves, their relations, and their manner of operation: or, secondly, that which man himself ought to do, as a rational and voluntary agent, for the attainment of any end, especially happiness: or, thirdly, the ways and means whereby the knowledge of both the one and the other of these is attained and communicated; I think science may be divided properly into these three sorts. Locke then elaborates on the

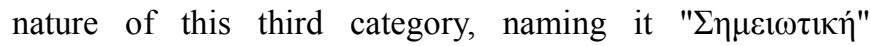
(Semeiotike), and explains it as "the doctrine of signs" in the following terms: Thirdly, the third branch [of sciences] may be termed $\sigma \eta \mu \varepsilon 1 \omega \tau 1 \kappa$, or the doctrine of signs, the most usual whereof being words, it is aptly enough termed also

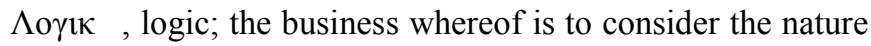
of signs the mind makes use of for the understanding of things, or conveying its knowledge to others." [1]

Ferdinand de Saussure $(1857$ - 1913) really put this problem on the agenda in his famous book "Course in 
General Linguistics", published in 1916. In it, he not only called words signs, but designated the science of studying them - semiology (in today's usage, semiotics):

"A science that studies the life of signs within society is conceivable; it would be a part of social psychology and consequently of general psychology; I shall call it semiology (from Greek semeion 'sign')."

He goes on:

"Semiology would show what constitutes signs, what laws govern them. Since the science does not yet exist, no one can say what it would be; but it has a right to existence, a place staked out in advance. Linguistics is only a part of the general science of semiology; the laws discovered by semiology will be applicable to linguistics, and the latter will circumscribe a well-defined area within the mass of anthropological facts." [2]

This excerpt combines a host of important foresights with a considerable number of unjustified assumptions. Semiotics, indeed, can and does offer its own recipes for understanding many linguistic problems, but it does not in any way replace specific linguistic approaches. Therefore, de Saussure was right, concluding his reflections with the words: "The true and unique object of linguistics is language studied in and for itself." [2]

Many years have passed since that time. A lot of scholars have returned to this topic. Let's refer only to the most outstanding of them who insisted on the linguistic character of semiotics. Algirdas Julien Greimas (1917-1992) was considered a very outstanding semiotician. But all of his research dealt exclusively with linguistic problems. True, his doctoral dissertation was devoted to fashion, but it only referred to the linguistic aspect of the problem.

Émile Benveniste (1902-1976) was the purest linguist, who devoted several works to semiotics. In the article "The Semiology of Language" he criticizes Charles Peirce and touches upon many semiotic problems, but he never gives his own classification of the signs, referring almost always to linguistic examples.

Linguistics has been and remains an independent scientific discipline; in no way does it become a part of the semiotics that is taking shape only in our days. Nevertheless, the laws of the origin and use of signs apply to linguistics in the same way as they apply to any other science. You just need to distinguish general semiotics from branch semiotics, concerning one or another specific sphere of material reality. Any human problem has as its own signs and sign systems belonging to this sphere; in mathematics there are its signs and sign systems developing according to their particular laws, in cartography - their own, etc. Linguistics in this regard is no different from other sciences or from various practices, like in crafts. In each of them there are signs that must be approached separately, as is customary in the given sphere of activity. These signs are usually collected in terminological dictionaries, and the ways of dealing with them depend on the metalanguage for a given concrete sphere.

Everything, that concerns the laws of the development of semiotic reality as a whole, is collected in general semiotics, which affects all types of particular semiotic manifestations, whether in linguistics or in some other sciences. In general semiotics, we are talking about any field of semiotics; and no one has yet succeeded in formulating the bulk of its laws. I offered my vision of them, proposing my own classification of signs (that is, all existing signs!) through the classification of different types of sign systems. Here it is, presented in the form of a taxonomic pyramid of sign systems "Figure 1":

\section{Types of sign-systems and the nature of the signs they employ}

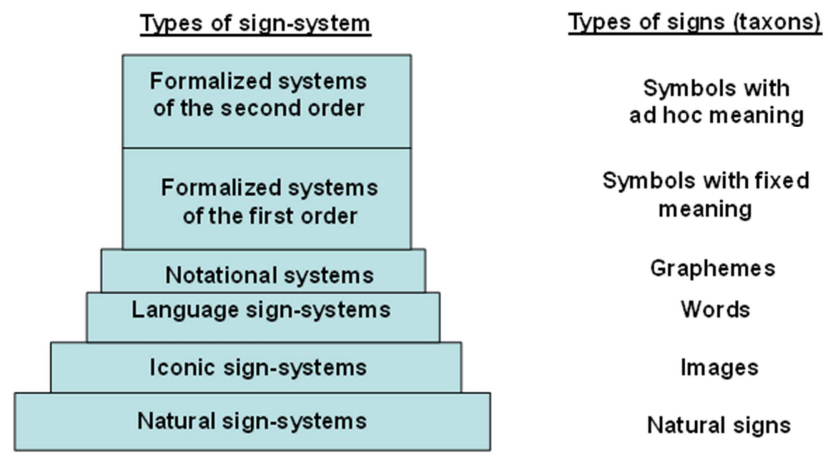

Figure 1. Types of sign systems.

"In Solomonick's General Semiotic theory, the six types of sign systems are arranged in a way that reflects both the order in which they appeared in human phylogenetic development (the development of the species as a whole, over time) and the order in which they appear ontogenetically in the understanding of each human being as they grow and develop.

At the inception of the human race, the first signs humans encountered and accepted as such, were natural signs. Every natural phenomenon served them as a sign; smoke was a sign of burning, darkness was a sign of approaching night, etc.

As people grew accustomed to these kinds of natural signs, they began to invent artificial signs as well. First, they invented signs that resembled the things they denoted images of their prototypes. Then they started to think up signs that were more and more remote from the things they signified. Thus, sign systems built upon words appeared, followed later by sign systems built on graphemes, and, finally, sign systems whose signs are entirely arbitrary mathematical signs and other symbols.

The theory of general semiotics arranges the types of sign systems in a hierarchy that reflects this gradual development. Each higher level in the hierarchy represents basic signs of more abstract character - more remote from the things they denote - than the basic signs of the level below it. This hierarchy is illustrated in the diagram above.

In the course of human development, each type of signs could only come into existence with the support of its predecessors. Furthermore, once it came into existence, each type of signs affected the further development of all previous 
types of signs. The various sign systems that have developed at each stage in human history, and their interdependence, have shaped the science and culture of every generation since the dawn of mankind. The collection of signs and sign systems that surround us at any given moment constitute the semiotic reality we use in our everyday life, in our scientific investigations, and in our cultural activities." [3]

The diagram above shows that the language type of sign systems is built on words as signs of a special type. It differs in its semiotic content from all other taxa shown in the scheme. It is situated in the very middle of the taxonomic ladder, which allows it to explain all other sign manifestations. Signs, which are less abstract than words, are raised to the level of verbal explanations, thus clarifying their content. And the taxa of higher abstraction are lowered by words to the level of words meaning, helping in this way those who, by their mental potential, cannot grasp them in their original form.

Understanding words as signs of special semiotic content, allows me to define anew what language is: "Language is $a$ sign system, in which the base sign is the word." Or: "The main purpose of language is to explain and accompany all things, events and phenomena that happen to us." The same circumstance makes it possible to distribute words within language according to their different levels of their abstractness (proper names $\rightarrow$ notions $\rightarrow$ concepts), as well as to draw other conclusions that cannot be based on purely linguistic considerations. This article is devoted to this particular topic.

\section{The Word as a Basic Semiotic Sign in All Languages}

Words constitute the basic linguistic signs in all the known natural languages, i.e. those languages used in everyday life. A recently-conducted survey under UN auspices indicates that about ten thousand natural languages exist in the world. All are word-based. I omit here the detailed discussion as to whether other linguistic units (morphemes, phonemes, or word combinations) may be considered the basic unit of the system, since it is clear inherently; they all are parts of words or their interplay. Suffice it to say that, from the semiotic viewpoint, a word in any language stands in relation to its referent in reality, and its psychological counterpart in the human mind - a notion (or idea) of an object.

That also distinguishes words - the basic signs of a language as a whole - from letters which are basic signs in the writing linguistic systems. Letters are counterparts of the language sounds, which are also represented by transcription characters. In this respect Blaise Paskal wrote in the XVII century: "Languages are ciphers, wherein letters are not changed into letters, but words into words, so that an unknown language is decipherable". [4].

Word is the basic unit also in artificial languages of the Esperanto type. Approximately one hundred such languages have been created artificially. Esperanto, the best known and most widely used, was originated by Lazar Zamenhof from a word stock of mostly classical origin (Greek and Latin) and a few rather simple linguistic rules. Esoteric language systems like drum- or whistle-languages are also word-oriented. Their sounds are based on special word tones used in the corresponding indigenous languages.

Do not be led astray by systems such as flag-signalling or Morse transmission. In these systems, flag movements and dot-dash combinations are the signs, and, as such, they are linguistic notation systems. They lead us to the same words written with the help of special signs. In this respect they are no different from a written text. Beyond the visible or auditory signs, we discover words of different languages; and our mind registers and processes them just like any other words.

Any word is an arbitrary sign, even our proper names. Besides the meaning attributed to it by de Saussure - i.e. there is "no organic bond between a word and its referent", a word is arbitrary also in the manner whereby it is conceived by people. We do not know how these connections were made by our forefathers, when they invented the very first linguistic words. We do know, however, how it is done today, because thousands of new words are introduced into any existing language during one's life span. They may be invented by chance inspiration; they may be motivated by a connection with words already in existence (in the same or other languages); more often than not they are preceded by a descriptive word combination, to be subsequently replaced by a single word. The choice of options is arbitrary and random.

Once it is made, the combination of sounds must be 'approved' by society. The process for attaining such approval is unfixed, and generally, long-lasting. A new word appears in speech, then in publications, gaining ever wider currency. If it succeeds in catching the public's imagination or the attention of scientific circles, it might enter the wordstock of the corresponding language, whereupon it would appear in standard dictionaries and begin to exert a false impression as if it existed always. In speaking of an object or phenomenon denoted by such a word, one must accept the word as its sign. If one appears unaware of it, he is to learn it anew and inject it where appropriate in the flow of communication. Gradually, these linguistic signs combine to produce the language we use.

Being an arbitrary sign, a word stands on a higher level of abstraction than a natural sign or most icons. It rarely resembles its referent. Only in very rare cases of the wordsign continuum, its sound combination may resemble the denoted phenomenon. Such words are onomatopoeic. Onomatopoeia embraces a small portion of the general word stock of any language and is, thus, the exception, rather than the rule. Nevertheless it is an exception that proves the rule: words are abstractions, and their meaning cannot be deciphered without proper teaching or instruction.

Another important characteristic of words is their numerical abundance. They are more numerous than in any other type of signs. They outnumber by far any notation or 
formalized program as well as any other signs in a natural or iconic system. This trait has a strong and lasting implication for language systems. Every system consists of a number of signs and processing rules. System users must learn both the signs and the rules. Users of a language system must, first of all, learn the words of a particular language. Nevertheless, since there are so many, nobody can master them all; consequently, word study (even in one's mother tongue) is open-ended. This also affects the rules for word enactment. Firstly, these rules are themselves very numerous and multifaceted (they must cover all kinds of words in all their combinations). Consequently, these rules are usually constructed like a chain: a rule $\rightarrow$ an exception to the rule $\rightarrow$ an exception to the exception, etc. Hence, the study of formal grammar is a protracted undertaking.

Another characteristic of language systems lies in their constant change and modification: some words drop out, new ones come up. This quality is based on the fact that words are signs that aspire to designate anything that occurs or exists in our surroundings, in ourselves and within our thoughts. And since these referents continually change, being appreciated anew, the word stock is also given to change and fluctuation, thus making language systems open-ended. Being such enormously huge systems, languages tend constantly to minimize their entropy; hence their ever-lasting trimming, also in the field of the word-stock.

Yet another characteristic is that a word-sign is systembound. Natural signs or images may act as signs without reference to a corresponding system. We may use a tree to mark our way home. A transparent image may reflect danger (a fire alarm, for example). This is not the case with a word. Since it is so abstract and conventional, a word cannot be understood properly outside its linguistic framework. This does not mean that we cannot use separate words; on the contrary, we constantly do so, but only as systemic signs, clarifying their systemic and extra-systemic meanings. This aids our understanding of the continuum of sign abstractness: pre-word signs can sometimes be understood without benefit of a system framework; words and hierarchically higher signs (notational and formalized) cannot.

All the aforementioned peculiarities of word-signs impact on the sign systems formed thereby, i.e. languages. We shall discuss their specifics in the next section.

\section{Languages as Sign Systems}

It is a strange feeling to give a fresh description to seemingly well-known phenomenon, which has been exhaustively examined by many outstanding linguists and philosophers. I mean my definition of what language is, which applies to any language in the world: language is a sign system consisting of words. And the reverse: words are the basic signs in any language. Nevertheless, the perspective offered here has never been used as a linguistic parameter, resulting in the fundamental properties of language being viewed in a new light. The basic problem of determining the main building blocks of language requires additional attention. Many linguists, of course, have dealt with the problem, and we shall discuss some of their opinions at length. For now, let us return to the crucial point: the word is the basic building block of language, because it is the symbolic counterpart of a denoted object in reality represented in our mind. This and other no less important arguments support the definition that a word is the main underpinning of languages. This means also that all other linguistic units derive from words - a very significant conclusion having practical implications for linguistics.

Thus, sub-units of words (morphemes, phonemes, separate sounds, etc.) should be viewed as parts of words. Larger constructions should also be considered as word-oriented. The word will be analyzed as a basis for all further alterations: we shall differentiate its morphologic base from its dictionary form. This base may differ from one alteration to another, and so forth. In short, many problems arise from our decision to choose word as the principal unit of the system.

The fact, so emphatically expressed by de Saussure, is that words are transformed (processed) along two main parameters: paradigmatic and syntagmatic. The first (paradigmatic) change implies that each word has a number of morphologic variables, one of which is enacted each time the word is so positioned. Every noun has case options, one of which is enacted when the noun requires a given case ending. Verbs have many paradigmatic possibilities (about three hundred word-forms in Korean); but only one wordform is enacted in each specific verb use. The syntagmatic parameter puts words into longitudinal chains, in which words are connected with one another. This second parameter sets directions for the previous - paradigmatic - changes: at a particular place in the chain a word acquires these and no other specific morphological characteristics, etc. Each language system has its own paradigmatic and syntagmatic rules (the latter group of rules is usually called syntax).

To use words in different positions, we divide them into morphemes - i.e., parts of words, each having its grammatical meaning, and reflecting the word's position within the paradigm-syntagm coordinates. The most prominent morpheme is the root - the unit underlying all other morphemes. Prefixes, suffixes, infixes and endings are added to roots to produce the necessary morpheme-syntactic modifications. Some have no extra-systemic meaning; their function is the syntactical organization of the linguistic system and have no lexical meaning (s).

Still other means serve to form compound words. In this regard, we are entering a wider - semantic - domain of wordmultiplication. Since any given language possesses so many words, there are rules of linguistic economy for creating new units. The limitations of human memory make this necessary.

The rules of economy permit the creation of new words which are transparent in their meaning to members of the relevant speech community. In English we usually revert to word combinations for this purpose. Here are examples from a page of Joyce's Ulysses: 'Sodachapped hands. Crusted toenails too.', 'basketchair', 'waxenfruit', 'There's whatdo- 
youcallhim out of'. It is customary for English to juxtapose several words, especially if they are related in their extrasystemic reality, to obtain a new word with gestalt meaning. English is a clear-cut example of a syntactic language having little morphology. By contrast, German is a language with a highly developed morphology, employing the same process to form new transparent words by means of suffixes and prefixes. Ostensibly, if you know the main German rootwords, constituting $15 \%-20 \%$ of the entire word stock, and the meaning of the most common suffixes and prefixes, you can successfully deduce the meaning of a further $30 \%$ of the vocabulary. In Semitic languages, such as Hebrew, we use infixes in verb-roots to produce verbs of predictable meaning (passive, causative and others).

The sign economy rules are expressed not only in the above manner, but in many other ways. Consider the number of derivatives from the nuclei of root words. First of all, there are groups of related words, having the same root. The very notion of a "root" is 'a common part of related words'. There are many kinds of relationships in these related words - some vague and incomprehensible. In most cases, however, knowledge of the root component, combined with grammatical sense of the word-building devices, helps us to guess correctly the meaning of many words we have never come across previously.

We can ascribe the number of derivative words to the result of conjugations and declensions. Imagine that, instead of regular changes, we had new and unintelligible words, as in the case of suppletion forms for different grammatical categories of the same word (like 'better' from 'good', etc.)! These are the means by which the gargantuan number of unknown words in language sign systems is kept to a minimum capacity of memory. Formulating the rules for word processing is the task of grammar. Listing all (or at least the vast majority of) the words is done by the dictionaries of particular languages. Some are considered more standard and reliable. Both grammars and dictionaries comprise what I call the metalanguage of a language sign system. Why is there more than one grammar and more than one dictionary for a given language?

Because a living natural language is always an open sign system, continually in flux, while grammars and dictionaries are restricted presentations of these open systems. These two trends never coincide completely, but are only more or less concurrent. The degree of their concurrency may delineate a dividing line between general and applied linguistics, but let us concentrate on the notion of metalanguage for linguistic sign systems.

\section{Metalanguages for Linguistic Sign Systems}

For millennia natural languages existed without metalanguages (i.e., grammars and dictionaries of natural languages). Grammars arose in ancient Greece, and dictionaries first appeared among Sumarians (as far as it is known). The pre-notational stage of language development is shrouded in mystery, and it is common knowledge that oral languages existed long before the invention of writing.

What is the semiotic significance of this? Firstly, the lower stages of sign system development did not require written, rigidly-fixed metalanguages. Natural systems are enacted without them. The same is true about the less abstracted images in the iconic systems. Language systems began to develop without them, but at some point, when languages became more complex, the absence of metalanguages impeded their further development, henceforth necessitating language analysis.

Secondly, mature language systems, such as modern languages, cannot develop normally without grammars and dictionaries; they all have both those aids - in quality and variety. And the converse is correct - those languages, which do not possess good grammars and dictionaries, cannot be considered mature and modern. All higher sign systems (notations and formalized ones) cannot even be conceived without having developed a metalanguage. This is also true of any artificial language invented today.

\subsection{A Short Historical Survey of the Development of Grammar}

The first attempts at introducing grammatical categories are found in Ancient Greece. Plato is considered the first one who distinguished between nouns (as entities about which an action or condition may be predicated) and verbs - as entities that predicate something about nouns. The same position was upheld by Aristotle, for whom anything that was not a noun or a verb was a conjunction. Their approach was logical, not grammatical, this being the stumbling block of subsequent generations of grammarians. Peter Salus writes:

"Following Protagoras, Aristotle divided the noun into three genders; and in the verb, he seems to have been the first person to consider tense in his definition. He also considered adjectives part of the verb class, for they predicated qualities of the noun; and he had unfortunate logical problems because of this. But nonetheless, Aristotle's categorizations had a profound influence upon later thought about language.'[5]

The next step in grammatical development lies with the Stoics:

"The earliest Stoic writers expanded Aristotle's three classes to four (noun, verb, conjunction, and article), and later Stoics increased this to five (dividing noun into proper and common nouns)... In the verb... they developed the theory of tenses... Within the group 'conjunction' the Stoics seem to have differentiated between prepositions and conjunctions, and in the article category, between pronouns and articles... The Stoics seem further to have been the first to study number and agreement in nouns and verbs, to study case in the noun, and the voice, mood and tense in the verb." [5]

"After the Stoics, the center of grammatical thought in the West shifted to Alexandria, and a whole school of Alexandrian grammarians arose during the first century BC. Chief among these grammarians was Dionysius Thorax. His 
grammatical treatise classified and represented the findings of others, and became the standard textbook for the next 1800 years. It was during the Alexandrian period that grammar finally gained status as a discipline..." [5]

And so it continued, while the western version of grammar attained its current image and significance. Worthy of note are the secondary developments and the philosophical points arising from this development.

Several centuries before the present era, Pãnini composed a grammar of Sanskrit, a Hindi language. It was only discovered and introduced into the linguistic mainstream in the 19th century. This was of immense significance for understanding not only of the connection between Sanskrit and the other Indo-European languages (which in itself was a great impetus for the further development of linguistics), but also for understanding the nature of grammar. Pãnini's grammar is the only grammar known to us which was composed independently of Greco-Roman patterns. All other grammars were written in accordance with the foundations already fixed by the ancient Greeks and Romans.

And what does this mean? That there are different ways to describe a language (a linguistic system); nevertheless, there are also general ideas lying at the foundation of all the systems. Thus, Pānini differentiated between different parts of words - roots, beginning particles, ending ones, sound shifts within roots - that altered the meaning of the words. His contemporary, Iaska (circa 500 BC), differentiated between verbs that could be changed (its main meaning was 'a process') and nouns, reflecting 'objects', and what we today call infinitives, denoting present actions.

Now, much later, in the 8th to 9th centuries AD, Semitic grammars (of Arabic and Hebrew) began to appear, which were very different from those of the Indo-European group. These first originated in Syria; however, it is well known that the writers of such grammars were guided by the Greek and Roman models in their possession. Still, they could not help but take into consideration the peculiarities of the languages they were describing. As a result, they discovered the concept of a Semitic verb-root, consisting of three consonant letters, and the concept of vowel infixes added to those roots to alter the meaning of words. The latter recalls what was mentioned about Sanskrit grammar, having no precedent in Greek and Roman grammars.

Can we conclude from this, as Chomski does, that grammatical notions are inbred in our minds? Emphatically not. The explanation may be that the logic of a language sign system somehow repeats (but is not equated with) the logic of real life found and registered by human beings in formal logical constructs. Languages, in turn, register this kind of logic; however, each language does it differently. Thus, the task of grammarians will always be to describe what is inherent to a particular language's way of reflecting reality, which at the same time will automatically lead them to the common ground and logical inferences of this reality. The attempt to present these two lines of analysis as independent entities created seemingly insurmountable difficulties, present in the various grammatical schools of thought throughout history.

We return to our grammar survey, but from the viewpoint which we have just mentioned:

"At about the same time (circa 12th century AD) we find Peter Helias in Paris, beginning the eight-hundred year history of what might be called philosophic grammar, with his commentary on Priscian. In his commentary, Peter seeks philosophic explanation for the rules set down by Priscian, and affirms that 'it is not the grammarian, but the philosopher who, carefully considering the specific nature of things, discovers grammar'." [5]

"Peter Ramus (born ca. 1515) is well known among the Renaissance grammarians. Ramus wrote Greek, Latin, and French grammars and set up a theory of grammar in his Scholae. He stressed the need to follow native speakers in modern languages as the key to usage. He is the most formal of the early grammarians, relying neither on semantics nor on logical categories, but on actual word forms." [5]

And here P. Salus reaches the conclusion:

"All of the grammatical works mentioned here fall into two of the Saussurian classes: speculative philosophy and grammar. The latter is here to be read as basically prescriptive grammar on the model of Dionysius Thrux and Priscian; the former is a more flexible concept. Beginning with Plato's pseudoetymologizing and passing through Peter of Spain's "Summulae", we find the question of the difference between the sign for something and the thing itself occurring again and again, along with the question of the arbitrariness of the linguistic sign. These very basic queries recur innumerable times in the history of grammatical theory and linguistics, and are perhaps only dispensed with in this century because of the clear and concise statement of Saussure." [5]

Salus is only partially right. Indeed, the resolution to the above contradiction was proposed by Saussure in his clearcut definition of the linguistic sign. Nevertheless, only a broader theory of sign systems can fully resolve the situation. Grammar consists of rules and principles affecting the entire language - not merely one sign. We must demonstrate how these rules reflect both the logical conclusions of people on what occurs in reality and the embodiment of these conclusions in linguistic forms, while speaking about the corresponding substance. There may be two (or more) vectors to investigate these matters, but all of them must take into consideration not only what we are speaking about but also the tools we use to convey our message. Only the concurrence of these two converging trends will yield satisfying results.

\subsection{Dictionaries as Tools for Representing Linguistic Units}

Grammar is only a part of a linguistic metalanguage. The second, and no less important part, is dictionaries. Dictionaries arose approximately coincidentally with the first grammars. More precisely, these two sources of information did not differ from each other at that stage. Let us take an example. In C. Gordon's book, we read:

"In 1850 Hincks discovered that the Babylonian script had 
been devised for another language, and Oppert gave that language the name we use now 'Sumarian'. The Akkadians regarded it as their classical language and therefore taught it in their scribal schools. To do this, they compiled bilingual vocabularies, bilingual grammatical exercises, interlinear translations, etc. [6]

Below I show an excerpt from the clay table with verbs in both Sumarian and Akkadian scripts "Figure 2" (see Figure 2).

This list of parallel words is considered to be the first dictionary in the world (circa 1000 BC). Naturally, the clay tablet is covered only in cúneiform, and the English transcriptions and translation are modern interpretations of the ancient languages. Nevertheless, the striking contents of the tablet are open to commentary.

This is actually a bilingual dictionary with one verb ("to weigh') in different tenses (past and future), in the third person singular and plural, with and without a direct object. Here we see Grammar at its inception, with forms familiar to the speech communities represented in two languages. The list of comparisons is presented in a specific order, from simpler grammatical forms to the more complex and difficult. It is hard to say whether the list can be classified - from our modern perspective - as a teaching aid, a grammatical explanation or a dictionary. Perhaps the most suitable definition would be that it is a representation of each of the three from the point where they were not yet defined as separate entities.

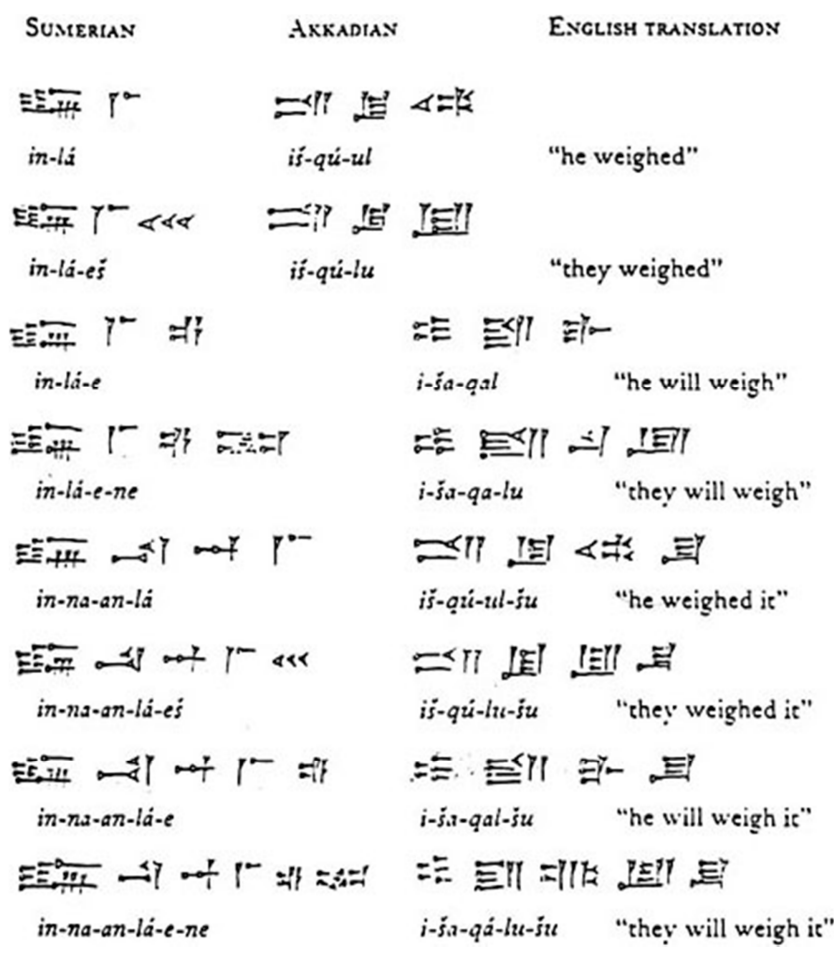

Figure 2. Excerpt from the ancient "dictionary".

There was a big commotion regarding these three related classifications that continued for years. Even on the threshold of the 'scientific' age, in the $17^{\text {th }}$ to $18^{\text {th }}$ centuries, we find a lack of distinctiveness regarding dictionaries, teaching manuals, and grammar. Linda C. Mitchell proved this point in her paper that she presented to the Euralex Conference in 1994:

"Comenius demonstrated his method by writing the popular Orbis Sensualium Pictus (1658), a staple of many schoolrooms. The book consists of a series of drawings in which each picture has numbers affixed to things he wants to name. Below the drawings are listed with vocabulary, translated from Latin... In this sense Orbis Sensualium Pictus functions as an early dictionary, although Comenius would not have called it that." $<\ldots>$ The author continues with more examples, concluding: "I want to argue... that the developments in the relations of grammar and lexicography do not constitute a progression so much as they do an inversion: in the beginning, grammar embraced lexicography, and later, lexicography embraced grammar." [7]

Even today lexicography is considered to be a fledgling profession. The title of one of the few manuals on lexicography makes this crystal clear: 'Lexicography. An Emerging International Profession'. [8] Moreover, there is no comprehensive theory of lexicography based on a comprehensive and broad based view of dictionaries. Such theory can be formulated only after languages are accepted as sign systems consisting of word-signs. Thus, like grammar, dictionaries should be considered a part of a language's metalanguage.

\section{The Logics of Language Systems}

It is very convenient to demonstrate here systemic kinds of logic using language systems as an example. I distinguish four kinds of such logics in any type of sign system including the linguistic ones. The first is logic of matching extrasystemic phenomena with that of their linguistic descriptions. While relating an occurrence from real life or discussing some proceedings, we try to convey real occurrence by linguistic means. We may do so by using different words and grammatical stratagems, but in all cases (if we do not intend to lie) we try to match what happened in reality. This is the first coordinate of our linguistic behavior.

But we use language systems not only for communication. We also try to meditate, organize and explain the different things around us by means of language. Then we use formal logic in all its diversity (the logic of syllogisms, deduction, induction, etc.). These modes of reasoning are expressed through words and statements. What is this kind of logic? It is the linguistic trappings of mundane observation. If we witness in our daily lives that every human being in our and everybody else's experience eventually reaches the end of his or her life, we reason that humans are mortal. The famous Aristotelian syllogism in this respect is only the linguistic formalization of the same conclusion. It is right that every formalization has an inherent contradiction, while pure reasoning and its formalization influence each other and the final result. That is why mathematical formalizations differ from linguistic ones; but, about this point, we must speak differently, while discussing mathematical systems. 
Language formalization not only allows us to express overtly the conclusions that we can also attain through observation, it adds a higher stage of reasoning by manipulating the logical means at our disposal. Through them, we can propose and make judgments on things not given to immediate observation. By using logical tools we can put forward unverifiable (in everyday life) and even hypothetical premises, and then manipulate them to reach otherwise unattainable conclusions. In many instances, this is the only way to attain certain conclusions.

Formal logic expressed linguistically appears to have acted satisfactorily in most approximations needed for our logical conclusions in most everyday activities and even in scientific matters (at any rate, in the humanities). When approximation in our reasoning needs to be more precise, we apply stricter mathematical sign systems. The difference here, as I see it, lies only in the degree of approximation. But already in language systems we find the difference between ordinary and formal thinking. I shall try to demonstrate this by comparing everyday reasoning to formal logical reasoning. Common everyday reasoning is based on observable facts and conclusions from such observations. Formal logical conclusions depend a) on more rigid procedures of reasoning and $b$ ) not only utilizing notions from everyday experience, but concepts - that is, units of scientific knowledge. In this way we guarantee greater accuracy in the conclusions we reach via language. The important point here is the difference between various word categories $-i$. e. notions and concepts.

The third kind of logic in language systems is systemic logic. This has nothing to do with matching or formal logic. This kind of logic is expressed by grammatical rules. In both English, Russian an attribute usually precedes the defined object: 'a red color' (красный цвет) or 'a big boy' (большой мальчик). In Hebrew, the same relation is expressed by the reverse order: ילד גדול or (do not forget that in Hebrew we read from right to left). English numerals refer to both noun genders without a change in form, while Hebrew numerals have special forms for each gender: 'ילד אחד =one boy' but 'ילדה אחת = one girl'. These "discrepancies" are normal for a natural language, but they do not influence the attainment of the same result in all languages.

The last kind of linguistic logic is the logic of application. While speaking of the same things, we adapt our language to different audiences. We not only alter the word stock, but also the syntactical constructions. The use of different language patterns for different age groups and for people beginning to study a language in comparison with those who master it, patently demonstrates my point.

Various combinations of all the above kinds of logic construct our language for us and our degree of its mastery. They are always present in our mind, whenever we use language.

\section{Summing up}

Language sign systems were introduced into human civilization when rudiments and even substantial gains were attained with the previously elaborated natural and iconic sign systems. The basic sign in all language systems is the word, whereas in natural sign systems some natural thing serves as a basic sign and in iconic systems image serves as the basic sign. Each of the three systems has different characteristics and presents its own inherent qualities. They represent very different modes of semiotics and should be considered separably.

Words, as signs of specific qualities, are capable to easily change their meanings, either acquiring some additional shade of the previous destination or gaining some rather conspicuously different deviation. These changes of word meanings go on along many dimensions. A word can acquire additional extra-systemic meaning like, for instance, in the course of the digital revolution many very concrete words gained special terminological implementations like "on the table', "windows", 'site", etc. They also can acquire another meaning because of grammatical shifts within the system; for example, by conversion it begins to serve not only as a noun but also as a verb. A word can acquire additional weight and meaning coming from a proper name to a notional position or from a notion to that of a concept. This shifts the quality and the weight of the word in the system, transferring the word to a different level of abstractness. In this respect, languages are open systems.

The last-mentioned property of language seems to be its substantial, if not principal characteristic. Languages ought to be open to new words, assimilating them into the overall structure; they must be ready to change their grammatical rules if they become obsolete. Otherwise, languages simply would be unable to exist. The more words it has and the more varied the rules for enacting these words, the better the language, both for communication and other purposes. The history of languages attests to the validity of this thesis. No one should be afraid of borrowing words from other languages, or of the changes going on continually in one's own language. The integration and assimilation of these novelties only improve language. Naturally, every rule has its limitations; and we must always remember the limitations of this particular rule so that the changes would be justifiable and based on common sense.

The said does not mean that the language systems are the most important ones in the semiotic hierarchy of systems and that linguistic properties are leading among all other sign systems. The well-known semiotician from Italy Susann Petrilly wrote in this respect: "The general theory and the related notion of the sign in general must avoid the limit often presented by semiotians, especially when it takes the form of semiology of Saussurian derivation. In other words, a general theory of signs must avoid glottocentrism. Glottocenrism means to refer to the verbal signs as the model of signs in general..." [9]

And that is absolutely correct. 


\section{References}

[1] At: https://en.wikipedia.org/wiki/Semiotics. Retrieved 1 July 2021.

[2] Full text of "Course in General L linguistics" is quoted here from: https://archive.org/stream/courseingenerall00saus/courseingen erallo0saus_djvu.txt.

[3] Abraham Solomonick Retrieved $1^{\text {st }}$ July 2021 from: https://en.wikipedia.org/wiki/Abraham_Solomonick.

[4] Blaise Pascal/Thoughts/Section 1.

[5] At: https://en.wikisource.org/wiki/Blaise_Pascal/Thoughts/Sec tion_1. Retrieved 17 July 2021.

[6] Peter H. Salus, On Language: Plato to von Humboldt, Holt, Renehart and Winston, 1959, p. 4.

[7] Gordon C. Forgotten Scripts, The story of their decipherment, London: Thames \& Hudson, p. 72.

[8] Mitchell LindaInversion of grammar books and dictionaries in the XVII and XVIII centuries. Proceedings of the Euralex Conference, 1994, p. 548. Also athttps://euralex.org/publications/inversion-of-grammarbooks-and-dictionaries-in-the-seventeenth-and-eighteenthcenturies/.

[9] At: Lexicography: An Emerging International Profession, (ed. by R. Ilson), London: Manchester University Press, 1986.

[10] Petrilly Susan. Ten theses for the future anterior of semiotics. The Bari school program of semiotics. At: http://www.susanpetrilli.com/files/ten-theses-for-the-futureanterior-of-semiotics.pdf. 